DOI:10.2478/rrlm-2018-0016

\title{
Serum hs-CRP, YKL-40 and brain-derived neurotrophic factor (BDNF) associated biomarkers in non-dipper hypertension profile?
}

\author{
Ioan Ţilea ${ }^{1}$, Andreea Varga $^{1 *}$, Septimiu Voidăzan², Adina Huţanu ${ }^{3}$ \\ 1. Family Medicine, Dept. M3-Internal Medicine, Faculty of Medicine, University of Medicine and \\ Pharmacy at Tirgu Mures, Romania \\ 2. Epidemiology, Dept.M2 Functional and additional sciences, Faculty of Medicine, University of \\ Medicine and Pharmacy at Tirgu Mures, Romania \\ 3. CCAMF, Dept. of Laboratory Medicine, University of Medicine and Pharmacy at Tirgu Mures, \\ Romania
}

\begin{abstract}
Background: Twenty-four hours dynamic blood pressure (BP) behaviour displays dipper profile defined as nocturnal systolic BP (SBP) reduction $>10 \%$ compared to daytime. Non-dipper profile, nocturnal absence of SBP fall, associates an increased cardiovascular risk. We investigated the concomitant association of inflammatory biomarkers - high-sensitivity-C-reactive protein (hs-CRP), Human Chitinase3-like1 (YKL-40) and autonomic nervous system (total brain-derived neurotrophic factor, BDNF) with respect to non-dipping blood pressure status.

Material and method: Using $24 \mathrm{~h}$ automatic BP measurements, 80 known hypertensive patients were divided into two groups: dipper group included fifty-one dipper patients (age $55.6 \pm 13.5$ years) and non-dipper group consisted of 29 non-dipper subjects (62.07 \pm 12.03 years). Serum levels of hs-CRP were evaluated with enhanced immunoturbidimetric assay. Plasma levels of YKL-40 were measured by commercial sandwich ELISA using microplate coated with a monoclonal antibody for CHI3L1. Plasma levels of total BDNF were determined using quantitative sandwich enzyme-linked immunoassay. Statistical analysis of obtained data was performed.

Results: In the non-dipper group, a significant positive association with age over 60 years, hs-CRP values above $1.90 \mathrm{mg} / \mathrm{dl}$ was observed along with increased mean values of YKL-40. Non-dipper status is independently and statistically significantly associated with elevated levels of hs-CRP (OR: 3.248, 95\% CI: 1.022-10.317, $p=0.046)$ in multivariate odds ratio analysis. No statistically significant positive association between a median total BDNF plasma level of $1430 \mathrm{pg} / \mathrm{ml}$ and the non-dipper hypertension profile was identified.

Conclusion: Our study demonstrated that patients over 60 years, in particular, have a higher probability to present a non-dipping pattern of hypertension. hs-CRP and YKL-40 values are more likely to increase in the non-dipping hypertensive patients, and hs-CRP values above $1.9 \mathrm{mg} / \mathrm{dl}$ can identify the presence of a non-dipper blood pressure profile.
\end{abstract}

*Corresponding author: Andreea Varga, University of Medicine and Pharmacy Tirgu Mures, Romania. E-mail: dr.andreeavarga@gmail.com 
Keywords: blood pressure, non-dipper pattern, cardiovascular risk, inflammatory biomarkers, autonomous nervous system

Received: 10 th February 2018; Accepted: $4^{\text {th }}$ May 2018; Published: 8h $^{\text {th }}$ July 2018

\section{Introduction}

Hypertension is one of the most prevalent cardiovascular $(\mathrm{CV})$ risk factors and represents the main cause of death worldwide. (1) The high prevalence of hypertension and the serious nature of the multiple negative consequences arising from hypertension have led to significant investigation of hypertension and triggers of abnormal circadian variation in blood pressure (BP). Previous research showed that hypertension profile can be defined by night-to-day ratio as either a dipper or a non-dipper pattern. The dipper profile is defined as a nocturnal systolic blood pressure (SBP) reduction $>10 \%$ of daytime SBP values, while non-dipper pattern is characterised by the absence of SBP fall during the night. (2) Hypertension profile has previously been associated with target organ damage (TOD) in hypertensive patients, while the non-dipper pattern has been associated with increased cardiovascular risk in both young and older populations. Furthermore, BP profile is a vital parameter to take into consideration during the management of hypertensive retinopathy in non-diabetic hypertensive patients. (3) Indeed, hypertensive patients exhibiting both non-dipper and reverse-dipper (SBP nocturnal upsurge) BP profiles have been associated with a significantly higher Framingham Stroke Risk Profile. (4)

Several factors have been reported to be directly related to hypertension dipping profile. Among these obstructive sleep apnoea and sleep quality were shown to influence the pattern of blood pressure in young and older hypertensive patients. (5)

Other research has investigated alterations in dysfunctional endothelium in response to changes in mechanical stress and the manner in which humoral factors can link inflammation with hypertension.(6) Human Chitinase3-like1 (YKL40, also known as human cartilage glycoprotein 39) belongs to the pentraxin family of proteins, stimulating cellular proliferation; it's role is explored as a non-disease-distinct inflammatory biomarker and/or tissue remodelling.(7) YKL40 can also exert a specific functional role in endothelial damage and is known to be involved in the restructuring and remodelling process in tissues during the course of atherosclerosis with concurrence in manifest $\mathrm{CV}$ disease.(8) As a materialized biomarker of $\mathrm{CV}$ disease, YKL-40 has been associated independently with myocardial ischaemia $(9,10)$, the presence and extent of coronary artery disease (CAD)(11) and patterns of atrial fibrillation.(12) YKL-40 levels in human serum or plasma increase with age, but within different age groups of healthy subjects, there is no circadian variability in relation to food intake and no association with gender.(13) In contrast, levels of this inflammatory glycoprotein in hypertensive patients correlate with the incidence of hypertension in a gender-specific manner.(14) Moreover, levels of YKL-40 are associated with age and reflect renal dysfunction in hypertensive patients with both coronary artery disease and diabetes mellitus (DM).(15)

Other markers, such as C-reactive protein (CRP) and high-sensitivity $\mathrm{C}$-reactive protein (hs-CRP), are strong predictors of CV outcomes (16) and show a positive correlation to impaired glomerular filtration rate in hypertensive patients. (17) Higher levels of hs-CRP were identified as predictors of a non-dipper pattern. (18)

Brain-Derived Neurotrophic Factor (BDNF) is an important neurotrophin that exhibits distinct control over the proposed course, evolu- 
tion and role of neural cells, and has also been demonstrated to show cardiovascular neuronal and non-neuronal involvement through autonomic neurons. (19)

In contempt of physiological autonomic nervous system (ANS) exert, circadian BP variation undergoes reversal in sympathetic activity decrease and parasympathetic activity increase during day to night. (20)

Our study aimed to identify a potential relationship between non-dipper status and three high cardiovascular risk biomarkers: serum hsCRP, YKL-40 and total BDNF levels.

\section{Material and method}

\section{Data Collection and Ambulatory Blood Pressure Monitoring (ABPM) profile}

A retrospective longitudinal study was performed on hypertensive patients from a cohort of 500 unselected patients presenting for routine investigation in a cardiology outpatient clinic. Between January 2016 and May 2016, eighty hypertensive patients (female to male ratio: $3: 5$ ) were enrolled. Patients with chronic kidney disease, heart failure New York Heart Association (NYHA) class III or IV, prior myocardial infarction and/or stroke, CAD, DM, malignant and non-malignant diseases characterized by inflammation (infectious diseases, rheumatoid arthritis, osteoarthritis, liver fibrosis) and chronic obstructive pulmonary disease were excluded.

Hypertensive patients were defined according to the $2013 \mathrm{ESH} / \mathrm{ESC}$ (European Society of Hypertension/European Society of Cardiology) Guidelines (21) taking continuous anti-hypertensive treatment for at least 6 months prior to admission.

All participants underwent ABPM using a BTL-08 ABPM recorder (BTL Industries, Stevenage, Hertfordshire, UK), according to a standardized protocol: $24 \mathrm{~h}$ of monitoring on the non-dominant arm, 70\% valid measurements, no validation for ABPM recording with more than two consecutive hours of invalidated records and pre-set time of day and night. Measurements during daytime were performed at intervals of 15 minutes and 30 minutes interval during night time. ABPM data were collected using BTL CardioPoint ${ }^{\circledR}$ solution (BTL Industries, Stevenage, Hertfordshire, UK). After analysing the 24-h BP measurement data, patients were divided into dipper or non-dipper profile groups. Dipper profile was defined as a drop of more than $10 \%$ of SBP (to a maximum of $20 \%$ ) during night time as compared with daytime. All other hypertensive profiles (including reverse dipper) not meeting the above-mentioned SBP pattern were included in the non-dipper pattern. (22)

\section{Methods for determining levels of hs-CRP, YKL-40, and total BDNF}

After detailed clinical evaluation, blood samples were collected (in the morning) by venepuncture in a clot activator tube for serum and ethylenediaminetetraacetic acid (EDTA) tubes for plasma. Samples were centrifuged at 3000 rpm for 15 minutes, and serum and plasma aliquots were stored at $-80^{\circ} \mathrm{C}$ until analysis.

High sensitivity-CRP serum levels were evaluated with an enhanced immunoturbidimetric assay $\left(\right.$ Cobas $^{\circledR}$ 6000, Roche Diagnostics $\mathrm{GmbH}$, Mannheim, Germany), with a measuring range between 0.15 and $20.0 \mathrm{mg} / 1$ and an extended measuring range (calculated) of 0.15 to 300 $\mathrm{mg} / \mathrm{l}$. Intra- and inter-assay coefficients of variation $(\mathrm{CVs})$ for this assay were $1.6 \%$ and $2.1 \%$, respectively.

Plasma levels of YKL-40 were measured using a commercially available sandwich enzyme-linked immunoassay (Human Chitinase3-like1 Elisa kit, Quantikine ${ }^{\circledR}$, R\&D Systems Inc, Minneapolis, MN, USA), using a microplate coated with a monoclonal antibody for CHI3L1. Plasma samples were diluted 50-fold, in accordance with the manufacturer's protocol. 
The analytical sensitivity was $3.55 \mathrm{pg} / \mathrm{ml}$, the measuring range between $0-4000 \mathrm{pg} / \mathrm{ml}$ and the $\mathrm{CVs}$ for intra- and inter-assay precision were $4.7 \%$ and $6.9 \%$, respectively.

Plasma levels of total BDNF were measured using a quantitative sandwich enzyme-linked immunoassay (Quantikine ${ }^{\circledR}$ R\&D Systems, Minneapolis, MN, USA). This method features a monoclonal antibody specific for BDNF that has been fixed on the microwells of the plate supplied with the kit and is able to recognize both the precursor and mature forms of BDNF from human plasma samples. For total BDNF measurement, platelet-poor plasma samples were diluted fivefold into appropriate diluent according to the manufacturer's instructions. The measuring range was between 0 and $1000 \mathrm{pg} / \mathrm{ml}$ with a minimum detectable limit of $0.997 \mathrm{pg} / \mathrm{ml}$; CVs for intra-assay and inter-assay precision were $3.0 \%$ and $4.7 \%$, respectively.

All serum and plasma specimens were analysed at the Center for Advanced Medical and Pharmaceutical Research, University of Medicine and Pharmacy of Tîrgu Mureş, Romania.

This research was reviewed and approved by the Ethics Committee for Scientific Research, University of Medicine and Pharmacy of Tîrgu Mureş, Romania. Each study participant provided informed signed consent.

\section{Statistical Analysis}

Statistical analysis was performed using the IBM SPSS Statistics for Windows, Version 25 (Armonk, NY, IBM Corp, USA) respectively MedCalc ${ }^{\circledR}$ version 17.4 (MedCalc Software BVBA, Ostend, Belgium) statistical software packages. Qualitative data are presented as counts and percentages. The association between qualitative variables was assessed using the Chi-square test with correction when necessary (Yates or Fisher's exact test). Quantitative data are presented as mean and standard deviation (for normally distributed data) and median/ min-max (for abnormally distributed data). To check for differences between two independent groups of quantitative data, Student's t-test and Mann-Whitney test were applied, according to the results of normality assessment.

The non-dipper and dipper status were assessed against several explanatory variables: age and gender, hs-CRP, YKL-40 and total BDNF. The relationship between non-dipper status and the explanatory variables being tested was assessed with binomial logistic regression.

When performing multivariate logistic analysis cardiovascular risk variables: male gender and age were classified as 1 .

In developing the multivariate logistic analysis, we selected all variables with a p-value less than 0.05 for univariate regression analysis, along with all variables of known clinical importance. Results are presented as coefficients/odds ratios (OR) and 95\% confidence intervals (CIs).

Blood pressure circadian profile (non-dipper and dipper) was considered as the dependent variable, with the risk variable represented by the non-dipper profile. Age, gender and biomarkers (hs-CRP, YKL-40 and total BDNF) were defined as independent variables. Male gender and age over 45 , respectively over 60 were defined as risk variables. Research conducted in European and Chinese populations analysed the investigation of risk factors in hypertensive patients over 45 years. The upper limit of 60 years was defined as the cut-off value by using literature data and data from the receiver operating characteristic (ROC) curve. $(23,14)$.

We used similar methods to estimate upper limits for hs-CRP, YKL-40 and total BDNF. A cut-off value was determined performing ROC curve analysis. (25) Positive prediction values were set at $1.9 \mathrm{mg} / \mathrm{dl}$ for hs-CRP, $0.702 \mathrm{pg} / \mathrm{ml}$ for YKL-40 and $500 \mathrm{pg} / \mathrm{ml}$ for BDNF.

For all statistical tests, the significance level alpha was set at 0.05 and two-tailed $p$ values were determined. 
In our intent to support other research directions, we performed a detailed comparative analysis of the antihypertensive drug classes used in the two study groups. A comparison between the overall mean ABPM values in dipper respectively non-dipper profile was also considered.

\section{Results}

We included eighty hypertensive patients with previously known stable antihypertensive therapy.

For further analysis we used the ROC analysis, related to the non-dipper and dipper BP profile, we calculated through the performance parameters, the power of independent variables: age, hs-CRP, YKL-40 and total BDNF, to influence the dependent variable (BP profile). (25)

Figure 1 presents the area under curve (AUC) for studied variables:

Age: AUC $=66.0 \%(\mathrm{CI} \%: 54.4-74.3)$

hs-CRP: $\quad$ AUC $=65.5 \% \quad(\mathrm{CI} \%: 53.1-78.2)$, sensibility $=82.8 \%, 95 \%$ CI:64.2-94.2, specificity $=47.1(32.9-61.5)$

YKL-40: $\quad \mathrm{AUC}=62.6 \% \quad(\mathrm{CI} \%: 49.5-75.6)$, sensibility $=65.5 \%, 95 \%$ CI:45.7-82.1, specificity $=58.8(\mathrm{CI} \%$ : 44.2-72.4)

Total BDNF: $\mathrm{AUC}=52.1 \%(\mathrm{CI} \%: 38.9-5.2)$, sensibility $=89.7 \%, 95 \%$ CI:72.6-97.8, specificity $=23.5$ (95\%CI:12.8-37.5).

Comparing AUC for the above mentioned variables, hs-CRP represents the powerful variable for identification non-dipper profile.

As mentioned in the material and method section, Figure 1 presents an example of the ROC curve analysis used to determine the cutoff values: $1.9 \mathrm{mg} / \mathrm{dl}$ for hs-CRP, $0.702 \mathrm{pg} / \mathrm{ml}$ for YKL-40 and $500 \mathrm{pg} / \mathrm{ml}$ for total BDNF. (25)

Detailed results of independent variables studied are presented in Table 1.

In our study group, non-dipper pattern was identified in $36.2 \%$ of studied hypertensive patients. Mean age of the non-dipper group was
$62.07 \pm 12.03$ years. For the dipper profile we identified $63.8 \%$ hypertensive patients with mean age for this profile of $55.6 \pm 13.5$ years. Statistically significant $(\mathrm{p}=0.03)$ differences were observed when analysing the mean age data between the non-dipper vs dipper group.

When analysing the mean age data across all hypertensive participants, we found no statistical difference $(p=0.25)$ between male $(62.5 \%$ of study population; mean age $56.6 \pm 13.4$ years) and female mean age (mean age $60.1 \pm 13.1$ years).

Age over 60 years showed statistically significant $(\mathrm{p}=0.02)$ positive association (OR:3.175, $95 \% \mathrm{CI}: 1.234$ to 8.047 ) with hypertension profile dependent risk variable - non-dipper pattern. We also observed a positive association of age over 45 years with the non-dipping pattern (OR:2.323, $95 \% \mathrm{CI}: 0.6023$ to 8.515$)$, but not statistically significant $(\mathrm{p}=0.23)$.

Male gender was negatively associated with non-dipping pattern (OR:0.489, 95\%CI:0.1912 to 1.226) with non-statistically significant

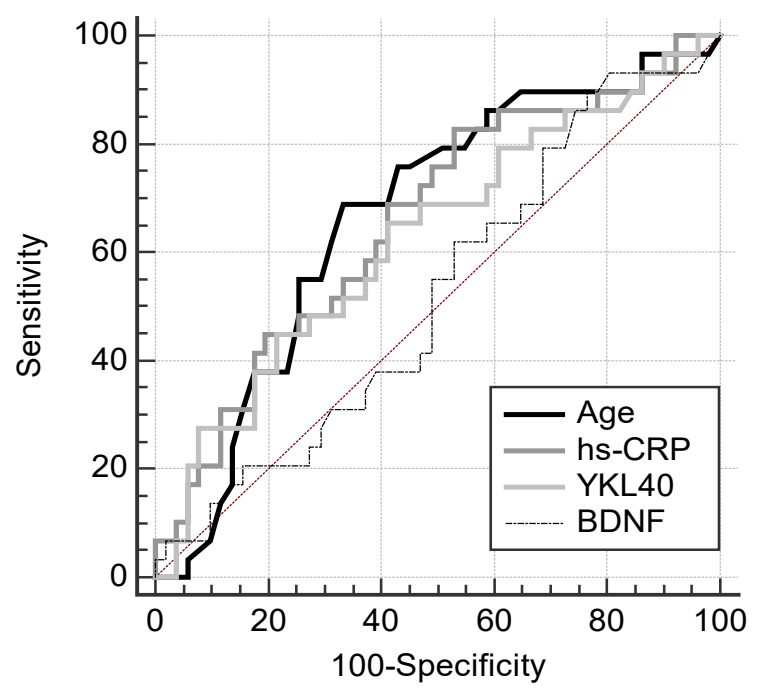

Fig. 1. The area under curve (AUC) for studied variables. Abbreviations: hs-CRP - high sensitivity C-reactive protein, YKL-40 - Human Chitinase3like1, BDNF - Brain-Derived Neurotrophic Factor. 
Table 1. Distribution of independent variables.

\begin{tabular}{|c|c|c|c|}
\hline \multirow[b]{2}{*}{ Variable } & \multicolumn{2}{|c|}{ Participant groups } & \multirow[b]{2}{*}{ P value } \\
\hline & $\begin{array}{c}\text { Non-dipper profile } \\
(\mathrm{n}, \%) \\
(29 \mathrm{pts}, 36.2 \%)\end{array}$ & $\begin{array}{c}\text { Dipper profile } \\
\text { (n, \%) } \\
(51 \text { pts, 63.8\%) }\end{array}$ & \\
\hline Age (years) (mean \pm SD) & $62.07 \pm 12.03$ & $55.6 \pm 13.5$ & $0.03 * * *$ \\
\hline \multirow{2}{*}{ Age>45 (years) } & $26(89.7)$ & $40(78.4)$ & \multirow{2}{*}{$\begin{array}{c}0.23 * \\
\text { (OR:2.323, 95\%CI:0.6023 to } 8.515 \text { ) }\end{array}$} \\
\hline & $3(10.3)$ & $11(21.6)$ & \\
\hline \multirow{2}{*}{ Age>60 (years) } & $20(69.0)$ & $21(39.2)$ & \multirow{2}{*}{$\begin{array}{c}0.02 * \\
\text { (OR:3.175, 95\%CI:1.234 to } 8.047)\end{array}$} \\
\hline & $9(31)$ & $30(60.8)$ & \\
\hline \multirow{2}{*}{ Gender (male) } & $15(51.7)$ & $35(68.6)$ & \multirow{2}{*}{$\begin{array}{c}0.13^{*} \\
\text { (OR:0.489, 95\%CI:0.1912 to } 1.226)\end{array}$} \\
\hline & $14(48.3)$ & $16(31.4)$ & \\
\hline $\begin{array}{l}\text { hs-CRP } \\
\geq 1.9 \mathrm{mg} / \mathrm{dl}\end{array}$ & 24 & 27 & \multirow{2}{*}{$\begin{array}{c}\text { 0.0006* } \\
\text { (OR:6.044, 95\%CI:2.141 to } 15.79)\end{array}$} \\
\hline $\begin{array}{l}\text { hs-CRP } \\
<1.9 \mathrm{mg} / \mathrm{dl}\end{array}$ & 5 & 24 & \\
\hline $\begin{array}{l}\text { YKL-40 } \\
\geq 0.702 \mathrm{pg} / \mathrm{ml}\end{array}$ & 19 & 22 & \multirow{2}{*}{$\begin{array}{c}0.09 * \\
(\text { OR:2.505, 95\%CI:0.9252 to 6.005) }\end{array}$} \\
\hline $\begin{array}{l}\text { YKL-40 } \\
<0.702 \mathrm{pg} / \mathrm{ml}\end{array}$ & 10 & 29 & \\
\hline $\begin{array}{l}\text { total BDNF } \\
\geq 500 \mathrm{pg} / \mathrm{ml}\end{array}$ & 26 & 40 & \multirow{2}{*}{$\begin{array}{c}0.238 * \\
(\text { OR:2.383, 95\%CI:0.6023 to } 8.515)\end{array}$} \\
\hline $\begin{array}{l}\text { total BDNF } \\
<500 \mathrm{pg} / \mathrm{ml}\end{array}$ & 3 & 11 & \\
\hline $\begin{array}{l}\mathbf{h s - C R P} \text { (mg/dl) } \\
\text { median (min-max) }\end{array}$ & $4.69(0.59-57.5)$ & $2.08(0.33-25.15)$ & $0.02 * *$ \\
\hline $\begin{array}{l}\text { YKL-40 (pg/ml) } \\
\text { median (min-max) }\end{array}$ & $0.83(0.25-2.64)$ & $0.63(0.17-3.30)$ & $0.04 * *$ \\
\hline $\begin{array}{l}\text { total BDNF (pg/ml) } \\
\text { median (min-max) }\end{array}$ & $1430(120-3360)$ & $1280(120-3350)$ & $0.76 * *$ \\
\hline
\end{tabular}

*Chi square test with corrections, ${ }^{* *}$ Mann-Whitney test no-number, ${ }^{* * *}$ Student's t-test

Abbreviations: hs-CRP - high sensitivity C-reactive protein, YKL-40 - Human Chitinase3-like1, BDNF - Brain-Derived Neurotrophic Factor, OR - odds ratio, $\mathrm{CI}$ - confidence interval.

$(p=0.13)$ difference between the number of male patients in the dipper and non-dipper pattern.

For the three studied biomarkers there is a statistically significant increase of the median value of hs-CRP $(p=0.02)$ and YKL-40 $(p=0.04)$ in the non-dipper profile group compared with the dipper group. For total BDNF median value, there is a surge of this biomarker median value in the non-dipper group, yet not statistically significant $(p=0.76)$ when compared with the median value of the dipper group.

Elevated hs-CRP value above $1.90 \mathrm{mg} / \mathrm{dl}$ ( sensibility $=82.8 \%$, specificity $=47.1 \%$ ) was statistically significant $(\mathrm{p}=0.0006)$ and positively associated (OR:6.044, 95\%CI:2.141 to 15.79) with the non-dipper hypertension profile. 
Although the YKL-40 plasma level higher than $0.702 \mathrm{pg} / \mathrm{ml}$ (sensibility $=65.5 \%$, specificity $=58.8 \%$ ) was positively associated (OR:2.505, 95\% CI:0.9252 to 6.005 ) with the non-dipper profile, it was not statistically significant $(\mathrm{p}=0.09)$ for patients presenting this pattern.

In univariate regression model, as shown in table 2, age, male gender, hs-CRP, YKL-40 and total BDNF plasma levels were considered related factors for the non-dipper pattern. Univariate regression analysis showed statistically significant $(p<0.05)$ relationship between the non-dipper profile and age over 60 years $(p=0.012)$, plasma levels of hs-CRP $(\mathrm{p}=0.01)$ and YKL-40 $(\mathrm{p}=0.039)$.

Multivariate odds ratio analysis, using information from the final logistic model of non-dipper profile, including only statistically significant variables according to the above mentioned univariate analysis, showed that only levels of hs-CRP $>1.9 \mathrm{mg} / \mathrm{dl}$ (OR:3.248, 95\% CI:1.02210.317) were independently statistically significant $(\mathrm{p}=0.046)$ and positively related with non-dipper status (OR:3.248). (Table 3).

In the two groups, the total number of patients taking a particular antihypertensive therapeutic drug class was comparatively assessed (table 4). For the use of sartans, there was a statistically significant $(\mathrm{p}=0.022)$ difference.
We also performed a statistical analysis of the mean values of ABPM data registered in the non-dipper vs dipper study group. There was no statistically significant $(\mathrm{p}<0.05)$ difference between the mean values of the non-dipper and dipper pattern. Results are reported in table 5.

\section{Discussion}

Long-term adverse outcomes and TOD are key directives in hypertension research. In particular, it is important to understand the mechanisms underlying the different high-risk patterns of hypertension. (26) Furthermore, the non-dipper pattern in treated hypertensive patients has been shown to be independently related to increased CV risk. ()

Table 3. Multivariate odds ratio from the final logistic model of non-dipper profile.

\begin{tabular}{lcccc}
\hline Variable & OR & \multicolumn{9}{c}{$\mathbf{9 5 \%}$ CI } & P value \\
\hline Age $>60$ (years) & 2.486 & 0.883 & 7.000 & 0.085 \\
\hline hs-CRP (mg/dl) & 3.248 & 1.022 & 10.317 & 0.046 \\
\hline YKL-40 (pg/ml) & 1.777 & 0.633 & 4.994 & 0.275 \\
\hline Abbreviations: hs-CRP - high sensitivity C-reactive pro- \\
tein, YKL-40 - Human Chitinase3-like1. \\
OR - odds ratio, CI - confidence interval. \\
Cut-off values: for hs-CRP above $1.9 \mathrm{mg} / \mathrm{dl}$, for YKL40 \\
above $0.702 \mathrm{pg} / \mathrm{ml}$.
\end{tabular}

Table 2. Univariate regressions for selected independent variables, in the non-dipper patients.

\begin{tabular}{|c|c|c|c|c|c|c|c|}
\hline \multirow{2}{*}{ Variable } & \multirow{2}{*}{ B } & \multirow{2}{*}{$\begin{array}{c}\text { Standard } \\
\text { error }\end{array}$} & \multirow{2}{*}{$\begin{array}{c}\text { Wald } \\
\text { test }\end{array}$} & \multirow{2}{*}{ P value } & \multirow{2}{*}{ OR crude } & \multicolumn{2}{|c|}{$95 \%$ CI for OR crude } \\
\hline & & & & & & Lower & Upper \\
\hline Age $>45$ (years) & 0.869 & 0.698 & 1.547 & 0.214 & 2.383 & 0.606 & 9.368 \\
\hline Age $>60$ (years) & 1.237 & 0.493 & 6.285 & 0.012 & 3.444 & 1.310 & 9.058 \\
\hline Sex (male) & -0.714 & 0.479 & 2.223 & 0.136 & 0.490 & 0.192 & 1.252 \\
\hline $\begin{array}{l}\mathbf{h s}-\mathbf{C R P}(\mathbf{m g} / \mathbf{d l}) \\
\text { (cut-off } 1.9 \mathrm{mg} / \mathrm{dl})\end{array}$ & 1.451 & 0.566 & 6.570 & 0.010 & 4.267 & 1.407 & 12.938 \\
\hline $\begin{array}{l}\text { YKL-40 (pg/ml) } \\
\text { (cut-off } 0.702 \mathrm{pg} / \mathrm{ml})\end{array}$ & 0.999 & 0.483 & 4.269 & 0.039 & 2.714 & 1.053 & 6.999 \\
\hline $\begin{array}{l}\text { total BDNF (pg/ml) } \\
\text { (cut-off } 500 \mathrm{pg} / \mathrm{ml} \text { ) }\end{array}$ & 0.00026 & .00022 & 1.001 & 0.90 & 0.999 & 0.990 & 1.0005 \\
\hline
\end{tabular}

Abbreviations: hs-CRP - high sensitivity C-reactive protein, YKL-40 - Human Chitinase3-like1, BDNF - Brain-Derived Neurotrophic Factor. OR - odds ratio, CI - confidence interval.

Cut-off values: for hs-CRP above $1.9 \mathrm{mg} / \mathrm{dl}$, for YKL40 above $0.702 \mathrm{pg} / \mathrm{ml}$, for total BDNF above $500 \mathrm{pg} / \mathrm{ml}$ 
Table 4. Drug classes used in studied hypertensive patients.

\begin{tabular}{lcccc}
\hline Drug therapy & Patients (n) & $\begin{array}{c}\text { Non-dipper profile } \\
\text { group (n, \%) }\end{array}$ & $\begin{array}{c}\text { Dipper profile } \\
\text { group (n, \%) }\end{array}$ & Pvalue* \\
\hline CCB & 48 & $18(37.5 \%)$ & $30(62.5 \%)$ & 0.108 \\
\hline BB & 49 & $19(38.8 \%)$ & $30(61.2 \%)$ & 0.140 \\
\hline ACE inhibitor & 18 & $6(33.3 \%)$ & $12(66.7 \%)$ & 0.576 \\
\hline Sartans & 36 & $14(38.9 \%)$ & $22(61.1 \%)$ & 0.022 \\
\hline Diuretics & 59 & $23(39.0 \%)$ & $36(61.0 \%)$ & 0.493 \\
\hline Statins & 63 & $24(38.1 \%)$ & $39(61.9 \%)$ & 0.598 \\
\hline
\end{tabular}

Abbreviations: CCB - calcium channel blockers, BB - beta-blockers, ACE inhibitor - angiotensin converting enzyme inhibitor, $\mathrm{n}$ - number.

*The therapeutic drug class was introduced as a variable, ordinary one way ANOVA test was used for calculating the $\mathrm{p}$ value.

Table 5 - Totalizer table. Blood pressure mean values in different subsets of hypertensive patients

\begin{tabular}{lcccc}
\hline & \multicolumn{3}{c}{ ABPM values (mmHg) } & Pvalue * \\
\cline { 2 - 4 } & $\begin{array}{c}\text { Overall group } \\
\text { (non-dipper + dip- } \\
\text { per) }\end{array}$ & $\begin{array}{c}\text { Non-dipper profile } \\
\text { group } \\
(\mathbf{n = 0 0})\end{array}$ & $\begin{array}{c}\text { Dipper profile } \\
\text { group } \\
\mathbf{( n = 5 1 )}\end{array}$ & $\begin{array}{c}\text { Non-dipper } \\
\text { vs } \\
\text { dipper }\end{array}$ \\
\hline Mean 24 h SBP & $130.68 \pm 14.26$ & $137.62 \pm 13.72$ & $126.74 \pm 13.12$ & 0.752 \\
\hline Mean 24 h DBP & $73.88 \pm 9.44$ & $76.24 \pm 10.21$ & $72.54 \pm 8.79$ & 0.564 \\
\hline Mean day SBP & $135.57 \pm 14.13$ & $138.17 \pm 15.04$ & $134.09 \pm 13.52$ & 0.458 \\
\hline Mean night SBP & $122.75 \pm 16.08$ & $135.93 \pm 14.50$ & $115.25 \pm 11.53$ & 0.968 \\
\hline Mean day DBP & $77.52 \pm 10.32$ & $77.79 \pm 11.25$ & $77.37 \pm 9.86$ & 0.471 \\
\hline Mean night DBP & $67.55 \pm 9.71$ & $73.41 \pm 10.61$ & $64.21 \pm 7.39$ & 0.770 \\
\hline
\end{tabular}

Abbreviations: ABPM - Ambulatory Blood Pressure Monitoring, SBP - systolic blood pressure, DBP - diastolic blood pressure.

* Kolmogorov-Smirnov normality test was performed, and paired sample t-test was used to calculate the $\mathrm{p}$ value.

Pierdomenico et al. (28) studied 1191 treated hypertensive patients who were 60 years of age and older, and demonstrated a positive correlation between the non-dipper pattern and the risk of coronary events.-

Our study including 80 hypertensive patients similarly demonstrated that an age increment may trigger an alteration of physiological BP profile. Particularly, patients over 60 years have a higher probability to present a non-dipping pattern of hypertension.

Previously published data described the hypothesis that increased inflammatory activity within the vessel endothelium is associated with higher levels of hs-CRP, increasing CV risk by engender hypertension and cardiovascular disease. $(29,30)$ Bakirci et al. (31) con- firmed that higher levels of YKL-40 and hs-CRP represent independent markers associated with the non-dipper profile in hypertensive patients. YKL-40 has previously been studied as a marker of inflammation, atherosclerosis, and endothelial dysfunction. $(8,32)$

Elevated values of inflammatory markers of endothelial dysfunction have been associated with the non-dipping pattern, findings that are consistent with the present study.

Our evidence indicates that hs-CRP and YKL-40 values are more likely to increase in the non-dipping hypertensive patients further enhancing the relevance of these markers in identifying high risk BP profile. Additionally, there is a strong possibility that hs-CRP values 
above $1.9 \mathrm{mg} / \mathrm{dl}$ can suggest the presence of a non-dipper BP profile.

Previous animal experiments have shown that BDNF appears to play a role in the regulation of hypertension via the ANS. (33). Plasma levels of BDNF correspond with those in the ANS and central nervous system, as suggested by Karege et al. (34) in a study conducted on rodents. However, very little is known about the role of the ANS in a non-dipping profile, particularly with respect to BDNF and abnormal circadian variation of BP. $(35,36)$

As various mechanisms are feasible for computing the non-dipping pattern, the present study assessed the ANS activity by assessing total BDNF plasma levels. Although, total BDNF levels certified a positive association to abnormal circadian variation of BP, there was no robust difference to dipper profile. We observed a greater median value in the non-dipping pattern of hypertensive studied patients.

Kasselman et al. (37) suggested that BDNF, as a neurotrophic factor can exert effect upon perivascular inflammation via stimulating effect on sympathetic neurons, and by creating sympathetic dysfunction in inflammatory disease. On the other hand, Kadoya et al. (38) reported a powerful association between reduced levels of BDNF in the plasma and a specific abnormal circadian variation in BP known as the reverse-dipper pattern. However, these authors also failed to demonstrate an association between plasma BDNF levels and non-dippers.

Our research suggests that age increment in the non-dipping hypertensive patients is related to an elevated combined response of the studied inflammatory biomarkers; in our non-dipper pattern patients, increasing age was not complementary with the ANS response activity. However, for hs-CRP values higher than $1.9 \mathrm{mg} / \mathrm{dl}$ determined independently of incident age over 60 years, the non-dipper status should be explored.
Supported by uni- and multivariate analysis, our data suggest that interventions targeting the hs-C-reactive protein may be used as in personalised approach of non-dipper hypertensive patients, independent of age, considering the BP profile as additional cardiovascular risk factor.

\section{Limitations}

Several limitations are associated with the current study. Firstly, all subjects were treated hypertensive patients that could have potentially influenced the biomarker levels in relation to circadian variations in SBP and BP values. We assume that different antihypertensive drug classes could interfere with dipping and non-dipping pattern, still our study did not intend to evaluate different therapeutic interactions in or with the hypertension profile. Secondly, day and night SBP variation was evaluated according to dayto-night ratio; no other parameters were used to evaluate BP variation, such as BP short-term variability or heart rate variability. Obstructive sleep apnoea was not assessed as possible confounding factor in hypertension profile. Thirdly, we did not consider potential fluctuation of 24-h plasma total BDNF concentrations in the present study. Results of the present study need to be documented in future prospective extended research.

\section{Conclusions}

To the best of our knowledge, our exploratory study was the first attempt to analyse the relationship between inflammation and ANS activity related to the non-dipping blood pressure status. In analysis, our observations indicate that in hypertensive patients aged over 60 years, the non-dipping pattern was associated with inflammatory response expressed by hs-CRP values higher than $1.9 \mathrm{mg} / \mathrm{dl}$ and YKL-40 values above $0.702 \mathrm{pg} / \mathrm{ml}$. Future research is needed to demonstrate the influence of ANS activity response regarding the non-dipping pattern. 
Based on results of our research in hypertensive patients aged over 45 years, particularly over 60 years, quantification of hs-CRP can be included in an extended evaluation panel of biomarkers reliable for investigating the circadian blood pressure variation.

\section{Acknowledgements}

This paper was partially supported by the University of Medicine and Pharmacy of Tîrgu Mureş, Romania, and SC Nova Vita Hospital SA Tîrgu Mureş, Internal Research Grant 6849/15.06.2015. All laboratory investigations were performed in collaboration and with the support of the Center of Advanced Medical and Pharmaceutical Research, University of Medicine and Pharmacy of Tîrgu Mureş, Romania.

\section{Author contributions}

TI: Conceptualization, resources, data curation, writing (reviewing and editing), supervision, funding acquisition, validation.

VA: Methodology, resources, writing (reviewing and editing), project administration, validation.

VS: Formal analysis, writing (original draft preparation), data curation, validation.

HA: Documentation, performed laboratory tests for hs-CRP, YKL-40 and total BDNF, writing (review and editing), visualization and validation.

\section{References}

1. Whelton PK, Carey RM, Aronow WS, Casey DE Jr, Collins KJ Dennison Himmelfarb C, et al. 2017 ACC/ AHA/AAPA/ABC/ACPM/AGS/APhA/ASH/ASPC/ NMA/PCNA Guideline for the Prevention, Detection, Evaluation, and Management of High Blood Pressure in Adults: A Report of the American College of Cardiology/American Heart Association Task Force on Clinical Practice Guidelines. Hypertension. 2017 pii: HYP.0000000000000065.
2. Verdecchia P, Schillaci G, Porcellati C. Dippers versus non-dippers. J Hypertens Suppl. 1991;9(8):S42-4.

3. Karadag B, Ozyigit T, Serindag Z, Ilhan A, Ozben B. Blood pressure profile is associated with microalbuminuria and retinopathy in hypertensive nondiabetic patients. Wien Klin Wochenschr. 2017. DOI: 10.1007/ s00508-017-1270-3. (Epub ahead of print). DOI: $10.1007 / \mathrm{s} 00508-017-1270-3$

4. Tsivgoulis G, Pikilidou M, Katsanos AH, Stamatelopoulos K, Michas F, Lykka A et al. Association of ambulatory blood pressure monitoring parameters with the Framingham Stroke Risk Profile. J Neurol Sci. 2017;380:106-111. DOI: 10.1016/j.jns.2017.07.007

5. Sekizuka H, Osada N, Akashi YJ. The factors affecting the non-dipper pattern in japanese patients with severe obstructive sleep apnea. Intern Med. 2018;57(11):15539. DOI: 10.2169/internalmedicine.0029-17

6. Cachofeiro V, Miana M, Heras N, Martin-Fernandez B, Ballesteros S, Balfagon G, et al. Inflammation: a link between hypertension and atherosclerosis. Curr Hypertens Rev. 2009;5(1):40-8. DOI: $10.2174 / 157340209787314333$

7. Lee CG, Da Silva CA, Dela Cruz CS, Ahangari F, Ma $\mathrm{B}$, Kang MJ et al. - Role of chitin and chitinase/chitinase-like proteins in inflammation, tissue remodeling and injury. Ann Rev Physiol. 2011;73:479-501. DOI: 10.1146/annurev-physiol-012110-142250

8. Rathcke CN, Vestergaard H. YKL-40 - an emerging biomarker in cardiovascular disease and diabetes. Cardiovasc Diabetol. 2009;8:61. DOI: 10.1186/14752840-8-61

9. Wang Y, Ripa RS, Johansen JS, Gabrielsen A, Steinbruchel DA, Friis T, et al. YKL-40 a new biomarker in patients with acute coronary syndrome or stable coronary artery disease. Scand Cardiovasc J. 2008;42(5):295302. DOI: $10.1080 / 14017430802220567$

10. Kastrup J, Johansen JS, Winkel P, Hansen JF, Hildebrandt $\mathrm{P}$, Jensen GB, et al. High serum YKL-40 concentration is associated with cardiovascular and all-cause mortality in patients with stable coronary artery disease. Eur Heart J. 2009;30(9):1066-72. DOI: 10.1093/ eurheartj/ehp049

11. Kucur M, Isman FK, Karadag B, Vural VA, Tavsanoglu S. Serum YKL-40 levels in patients with coronary artery disease. Coron Artery Dis. 2007;18(5):391-6. DOI: 10.1097/MCA.0b013e328241d991

12. Henningsen KM, Therkelsen SK, Johansen JS, 
Bruunsgaard H, Svendsen JH. Plasma YKL-40, a new biomarker for atrial fibrillation? Europace. 2009;11(8):1032-6. DOI: 10.1093/europace/eup103

13. Johansen JS. Studies on serum YKL-40 as a biomarker in diseases with inflammation, tissue remodelling, fibroses and cancer. Dan Med Bull. 2006;53(2):172-209.

14. Xu T, Zhong C, Wang A, Guo Z, Bu X, Zhou Y, et al. YKL-40 Level and hypertension incidence: a population-based nested. case-control study in China. J Am Heart Assoc. 2016;5(11):e004534. DOI: 10.1161/ JAHA.116.004534

15. Churakova E, Shubina A; Bolotina, M, Masenko V, Karpov Y. New inflammatory marker YKL-40 is associated with early renal function decline in hypertensive patients with concomitant coronary artery disease and type 2 diabetes mellitus. J Hypertens. 2017;35, e-Supplement 2.

16. Rutter MK, Meigs JB, Sullivan LM, D'Agostino RB Sr, Wilson PW. C-reactive protein, the metabolic syndrome, and prediction of cardiovascular events in the Framingham Offspring Study. Circulation. 2004;110(4):380-5. DOI: 10.1161/01.CIR.0000136581.59584.0E

17. Shu HS, Tai YY, Chang KT, Chu CY, Hsu PC, Ho-Ming $\mathrm{Su}$, et al. Plasma high-sensitivity C-reactive protein level is associated with impaired estimated glomerular filtration rate in hypertensives. Acta Cardiol Sin 2015;31(2):91-7.

18. Buyukkaya E, Erayman A, Karakas E, Bugra Nacar A, Kurt M, Buyukkaya S, et al - Relation of red cell distribution width with dipper and non-dipper hypertension. Med Glas (Zenica) 2016;13(2):75-81.

19. Pius-Sadowska E, Machaliński B. BDNF - A key player in cardiovascular system. J Mol Cell Cardiol. 2017;110:54-60. DOI: 10.1016/j.yjmcc.2017.07.007. DOI: 10.1016/j.yjmcc.2017.07.007

20. Sherwood A, Steffen PR, Blumenthal JA, Kuhn C, Hinderliter AL. Nighttime blood pressure dipping: the role of the sympathetic nervous system. Am J Hypertens. 2002;15 (2 Pt 1):111-8. DOI: 10.1016/S08957061(01)02251-8

21. Mancia G, Fagard R, Narkiewicz K, Redon J, Zanchetti A, Böhm M, et al. 2013 ESH/ESC Guidelines for the management of arterial hypertension: The Task Force for the management of arterial hypertension of the European Society of Hypertension (ESH) and of the European Society of Cardiology (ESC). Eur Heart J, 2013;34(28):2159-219. DOI: 10.1093/eurheartj/eht151
22. Verdecchia P, Porcellati C, Schillaci G, Borgioni C, Ciucci A, Battistelli M, et al. Ambulatory blood pressure. An independent predictor of prognosis in essential hypertension. Hypertension. 1994;24(6):793-801. DOI: 10.1161/01.HYP.24.6.793

23. Niiranen TJ, Jula AM, Kantola IM, Reunanen A. Comparison of agreement between clinic and home-measured blood pressure in the Finnish population: the Finn-HOME Study. J Hypertens. 2006;24(8):1549-55. DOI: 10.1097/01.hjh.0000239290.94764.81

24. Liu X, Liu C, Schenck H, Yi X, Wang H, Shi x. The risk factors of 9-year follow-up on hypertension in middle-aged people in Tujia-Nationality settlement of China. J Hum Hypertens. 2017;31(12):838-42. DOI: 10.1038/jhh.2017.58

25. Habibzadeh F, Habibzadeh P, Yadollahi M. On determining the most appropriate test cut-off value: the case of tests with continuous results. Biochem Med (Zagreb). 2016; 26(3): 297-307. DOI: 10.11613/BM.2016.034

26. Jimenez MC, Rexrode KM, Kotler G, Everett BM, Glynn RJ, Lee IM et al. Association between markers of inflammation and total stroke by hypertensive status among women. Am J Hypertens. 2016;29(9):1117-24. DOI: 10.1093/ajh/hpw050

27. Pierdomenico SD, Pierdomenico AM, Coccina F, Lapenna D, Porreca E. Circadian blood pressure changes and cardiovascular risk in elderly-treated hypertensive patients. Hypertens Res. 2016;39(11):805-11. DOI: 10.1038/hr.2016.74

28. Pierdomenico SD, Pierdomenico AM, Di Tommaso R, Coccina F, Di Carlo S, Ettore Porreca E, et al. Morning blood pressure surge, dipping, and risk of coronary events in elderly treated hypertensive patients. Am J Hypertens. 2016;29(1):39-45. DOI: 10.1093/ajh/ hpv074

29. Yousuf O, Mohanty BD, Martin SS, Joshi PH, Blaha MJ, Nasir K, et al. High-sensitivity C-reactive protein and cardiovascular disease: a resolute belief or an elusive link? J Am Coll Cardiol. 2013;62(5):397-408. DOI: 10.1016/j.jacc.2013.05.016

30. Tosu AR, Demir S, Selcuk M, Kaya Y, Akyol A, Ozdemir $\mathrm{M}$, et al. Comparison of inflammatory markers in non-dipper hypertension vs. dipper hypertension and in normotensive individuals: uric acid, C-reactive protein and red blood cell distribution width readings. Postepy Kardiol Interwencyjnej. 2014;10(2): 98-103. DOI: 10.5114/pwki.2014.43514 
31. Bakirci EM, Degirmenci H, Hamur H, Gunay M, Gulhan B, Aydin M, et al. - New inflammatory markers for prediction of non-dipper blood pressure pattern in patients with essential hypertension: Serum YKL-40/Chitinase 3-like protein 1 levels and echocardiographic epicardial adipose tissue thickness. Clin Exp Hypertens. 2015;37(6):505-10. DOI: 10.3109/10641963.2015.1013122

32. Rathcke CN, Vestergaard H. YKL-40, a new inflammatory marker with relation to insulin resistance and with a role in endothelial dysfunction and atherosclerosis. Inflamm Res. 2006;55(6):221-7. DOI: 10.1007/s00011006-0076-y

33. Vermehren-Schmaedick A, Jenkins VK, Hsieh HY, Brown AL, Page MP, Brooks VL, et al. Upregulation of brain-derived neurotrophic factor expression in nodose ganglia and the lower brainstem of hypertensive rats. J Neurosci Res 2013;91(2):220-9. DOI: 10.1002/ jnr.23158

34. Karege F, Schwald M, Cisse M. Postnatal developmental profile of brain-derived neurotrophic factor in rat brain and platelets. Neurosci Lett. 2002;328(3): 261- 4 .
DOI: 10.1016/S0304-3940(02)00529-3

35. Hojo Y, Noma S, Ohki T, Nakajima H, Satoh Y. Autonomic nervous system activity in essential hypertension: a comparison between dippers and non-dippers. J Hum Hypertens. 1997;11:665-71. DOI: 10.1038/sj. jhh.1000515

36. Sherwood A, Steffen PR, Blumenthal JA, Kuhn C, Hinderliter AL. Nighttime blood pressure dipping: the role of the sympathetic nervous system. Am J Hypertens. 2002;15(2 Pt1): 111-8. DOI: 10.1016/S08957061(01)02251-8

37. Kasselman LJ, Sideris A, Bruno C, Perez WR, Cai N, Nicoletti JN, et al. BDNF: a missing link between sympathetic dysfunction and inflammatory disease? J Neuroimmunol. 2006;175(1-2):118-27. DOI: 10.1016/j. jneuroim.2006.03.008

38. Kadoya M, Koyama H, Kanzaki A, Kurajoh M, Hatayama M, Shiraishi J, et al. Plasma brain-derived neurotrophic factor and reverse dipping pattern of nocturnal blood pressure in patients with cardiovascular risk factors. PLoS One. 2014;9(8):e105977. DOI: 10.1371/ journal.pone.0105977 